\title{
Long non-coding RNA MIAT promotes the proliferation and invasion of laryngeal squamous cell carcinoma cells by sponging microRNA-613
}

\author{
FUCUN SONG, YANG YANG and JIXIANG LIU \\ Department of Otolaryngology Head and Neck Surgery, Tianjin Union Medical Center, Tianjin 300121, P.R. China
}

Received November 22, 2019; Accepted November 24, 2020

DOI: $10.3892 /$ etm.2021.9663

\begin{abstract}
Accumulating evidence indicates that the long non-coding RNA myocardial infarction associated transcript (lncRNA MIAT) serves an important role in the progression of a number of cancer types. However, the precise molecular mechanism of MIAT in laryngeal squamous cell carcinoma (LSCC) progression remain elusive. The aim of the current study was to assess the effects and to clarify the molecular mechanism of MIAT on the proliferation and invasion of LSCC cells. The expression of MIAT was detected in LSCC tissues and cells using reverse transcription-quantitative PCR. MTT and colony formation assays were performed to examine the effects of MIAT on the proliferation of LSCC cells. Additionally, wound healing and Transwell experiments were employed to examine cellular migration and invasion. Luciferase reporter gene assay was also used to confirm the direct binding between MIAT and microRNA (miR)-613 in LSCC cells. An RNA immunoprecipitation assay was performed to verify the interaction between MIAT and miR-613. In the present study, it was found that the expression of MIAT in LSCC tissues was markedly higher compared with that in adjacent non-tumor tissues. In addition, MIAT expression was also increased in the human LSCC cell lines TU686, TU-177 and AMC-HN-8 compared with that in normal human keratinocytes (HaCaT). Knocking down MIAT expression significantly reduced LSCC cell proliferation and inhibited colony formation, a shown by MTT and colony formation assays, respectively. MIAT knockdown also substantially inhibited the migratory and invasive abilities of LSCC cells, as shown by wound healing and Transwell invasion assays, respectively. Subsequently, luciferase reporter assays verified that MIAT could bind to miR-613, where a negative correlation was observed between the expression of
\end{abstract}

Correspondence to: Dr Fucun Song, Department of Otolaryngology Head and Neck Surgery, Tianjin Union Medical Center, 190 Jieyuan Road, Hongqiao, Tianjin 300121, P.R. China E-mail: tjrmyang@163.com

Key words: laryngeal squamous cell carcinoma, long non-coding RNA, myocardial infarction associated transcript, proliferation, invasion
MIAT and miR-613 in LSCC tissues. Suppression of miR-613 partially reversed the inhibitory effects of MIAT knockdown on the proliferation, migration and invasion of LSCC cells. Taken together, the present study identified that MIAT may function as an oncogenic IncRNA to promote LSCC progression, which provides a potential therapeutic target or as a novel diagnostic biomarker for LSCC.

\section{Introduction}

Laryngeal squamous cell carcinoma (LSCC) is one of the most common types of malignant tumors in the larynx (1). According to Global Cancer Statistics 2018, there are 94,771 deaths from laryngeal carcinoma worldwide, which presents $1 \%$ of all cancer types (2). Due to rapid progression, invasive growth, frequent lymph node and distant metastasis and poor prognoses, LSCC severely affects the quality of life $(3,4)$. However, the molecular mechanism and pathogenesis underlying LSCC remain poorly understood. Therefore, understanding the molecular mechanisms that are involved in LSCC development and progression, in addition to the identification of novel therapeutic targets are of utmost importance.

Long non-coding RNAs (lncRNAs) belong to a family of RNAs that is $>200$ nucleotides in length and can function as either oncogenes or tumor suppressors (5-7). Accumulating evidence has suggested that lncRNAs serve a role in cell proliferation, metastasis, apoptosis and angiogenesis in $\operatorname{LSCC}(8,9)$. Elucidation of the role of lncRNAs in LSCC may provide novel insights into the occurrence and progression of LSCC. IncRNA nuclear enriched abundant transcript 1 (NEAT1) expression was found to be upregulated in LSCC tissues and cell lines, which negatively correlated with miR-107 expression in LSCC tissues (10). NEAT1 was subsequently reported to promote the proliferation and cell cycle arrest at the $G_{1}$ phase, and inhibit the apoptosis of LSCC cells by regulating the microRNA (miR)-107/cyclin-dependent kinase (CDK) 6 pathway (10). In addition, lncRNA antisense non-coding RNA in the INK4 locus has been reported to server a role in the proliferation, apoptosis, invasion and migration of LSCC cells by sponging miR-181a (11).

Myocardial infarction associated transcript (MIAT) is a novel lncRNA located on chromosome $22 \mathrm{q} 12$ that was originally identified to be involved in the pathogenesis myocardial infarction (12). Previous studies indicate that lncRNA MIAT 
serves an important role in the progression of various types of cancer (13-16). A study in gastric cancer suggested that MIAT knockdown inhibited gastric cancer cell growth and metastasis both in vitro and in vivo (13). Another study previously reported that the expression of MIAT in non-small-cell lung cancer (NSCLC) tissues was upregulated, whereby knockdown of MIAT substantially inhibited the invasive ability of NSCLC cells (14). Additionally, Liu et al (16) documented that the level of MIAT expression was upregulated in colorectal cancer (CRC) tissues and cells, such that MIAT knockdown inhibited proliferation, migration and invasion whilst enhancing apoptosis in CRC cells (16). However, to date, the precise function of IncRNA MIAT in LSCC remains poorly understood. Therefore, the present study aimed to investigate the expression and roles of MIAT in LSCC tumorigenesis. The current study detected the expression of MIAT in LSCC tissues and cells through reverse transcription-quantitative PCR (RT-qPCR). The proliferation, migration and invasion of cells was assessed by MTT, wound healing and Transwell assays, respectively. Furthermore, experiments were performed to clarify the mechanism of MIAT in LSCC progression.

\section{Materials and methods}

Patient tissue samples and LSCC cell lines. A total of 32 pairs of human LSCC tissue samples and corresponding adjacent non-tumor tissues $(>2 \mathrm{~cm}$ away from the tumor site) were collected from the Tianjin Union Medical Center (Tianjin, China) between June 2015 and January 2018. The patients included 26 males and 6 females, with an average age of 59 years $(59 \pm 7.8)$. The categories of all LSCC tissues was confirmed using pathological analysis according to the WHO pathology and genetic classification of tumors of the head and neck (17). The tissue samples were immediately frozen in liquid nitrogen and then stored at $-80^{\circ} \mathrm{C}$ for further research. The patients were diagnosed with LSCC without radiotherapy or chemotherapy prior to surgery. The exclusion criteria for patients included hepatic and renal insufficiency, immune deficiency and other systemic malignancies. All patients signed informed consent prior to the use of their tissues for the present study according to the principles of the Declaration of Helsinki. The present study was approved by the Ethics Committee of Tianjin Union Medical Center.

LSCC cell lines TU-177 and AMC-HN-8 and the normal human keratinocyte cell line $\mathrm{HaCaT}$ were purchased from the American Type Culture Collection. HaCaT cells are immortalized human epidermal cells that has been previously used as the control cell line for laryngeal squamous cell carcinoma cells $(18,19)$. The LSCC cell line TU686 was purchased from the Cell Center of Life Science of Chinese Academy of Science.

Cell culture and transfection. All cells were cultured in DMEM (Invitrogen; Thermo Fisher Scientific, Inc.) supplemented with 10\% FBS (Gibco; Thermo Fisher Scientific, Inc.), $100 \mathrm{IU} / \mathrm{ml}$ of penicillin and $100 \mu \mathrm{g} / \mathrm{ml}$ of streptomycin at $37^{\circ} \mathrm{C}$ in a humidified atmosphere with $5 \% \mathrm{CO}_{2}$.

Small interfering RNA (siRNA) containing the specific MIAT interference sequence (si-MIAT, 5'-CCA GGCUCCUUUAAACCAATT-3') and negative control
(si-NC, 5'-UUCUCCGAACGUGUCA-3') were purchased from Shanghai GeneChem Co., Ltd. miR-613 mimics (5'-AGGAAU GUUCCUUCUUUGCC-3'), miR-NC (5'-UUCUCCGAACGU GUCACGUTT-3'), anti-miR-613 (5'-GGCAAAGAAGGA ACAUUCCT-3') and anti-miR-NC (5'-CAGUACUUUUGU GUAGUACAA-3') were purchased from Guangzhou Ribobio Co., Ltd. A total of $100 \mathrm{nM}$ si-MIAT, $100 \mathrm{nM}$ si-NC, $50 \mathrm{nM}$ miR-613 mimics, $50 \mathrm{nM}$ anti-miR-613 and $50 \mathrm{nM}$ of their corresponding negative controls were transfected into LSCC cells using the Lipofectamine ${ }^{\circledR} 2000$ reagent (Invitrogen; Thermo Fisher Scientific, Inc.) following the manufacturer's protocol. After $48 \mathrm{~h}$ of transfection, the cells were collected for subsequent experimentation.

$R T-q P C R$. Total RNA was extracted from the cultured cells or fresh surgical tissue samples using TRIzol ${ }^{\circledR}$ reagent (Invitrogen; Thermo Fisher Scientific, Inc.) according to the manufacturer's protocols. Subsequently, cDNA was synthesized using the PrimeScript ${ }^{\mathrm{TM}}$ RT Reagent kit (Takara Bio, Inc.). The temperature protcol was as follows: $15 \mathrm{~min}$ at $42^{\circ} \mathrm{C}$ and $5 \mathrm{sec}$ at $85^{\circ} \mathrm{C}$. qPCR was performed using the All-in-One ${ }^{\mathrm{TM}}$ miRNA qRT-PCR detection kit (GeneCopoeia, Inc.) for miR-613, where U6 was used as an endogenous control. The expression level of MIAT mRNA was detected using the SYBR Premix Ex Taq ${ }^{\mathrm{TM}}$ II kit (cat. no. DRR081A; Takara Bio, Inc.) in accordance with manufacturer's protocol, where GAPDH was used as an endogenous control. The thermocycling conditions were as follows: $30 \mathrm{sec}$ at $95^{\circ} \mathrm{C}$, followed by 40 cycles for $5 \mathrm{sec}$ at $95^{\circ} \mathrm{C}$ and $35 \mathrm{sec}$ at $60^{\circ} \mathrm{C}$. The sequences of the primers were as follows: MIAT forward, 5'-TCTTCA TGTCAGAACACGCTTTA-3' and reverse, 5'-AAGGTCACC CGAGGTCCAA-3'; GAPDH forward, 5'-AGGTGAAGG TCGGAGTCAACG-3' and reverse, 5'-AGGGGTCATTGA TGGCAACA-3'; miR-613 forward, 5'-CGCAGCACACCT GCTTTTTG-3' and reverse, 5'-AGAGATTCGGGTCGATGC TC-3' and U6 forward, 5'-CTCGCTTCGGCAGCACA-3' and reverse, 5'-AACGCTTCACGAATTTGCGT-3'. The relative expression levels of detective genes were calculated using the $2^{-\Delta \Delta C t}$ method (20).

MTT assay. MTT assay was used to examine cell viability. TU-177 and AMC-HN-8 cells ( $5 \times 10^{3} /$ well) were seeded into 96-well plates and allowed to grow for 12, 24, 48 and $72 \mathrm{~h}$ at $37^{\circ} \mathrm{C}$. Subsequently, $20 \mu \mathrm{l} \mathrm{MTT}(5 \mathrm{mg} / \mathrm{ml}$; Sigma-Aldrich; Merck $\mathrm{KGaA}$ ) were added into each well and the plates were incubated at $37^{\circ} \mathrm{C}$ for additional $4 \mathrm{~h}$. The optical density (OD) value of each well was detected using an iMark microplate absorbance reader (Bio-Rad Laboratories, Inc.) at $570 \mathrm{~nm}$. All the experiments were performed three times.

Colony-formation assay. The LSCC cells were seeded into six-well plates at a density of 500 cells per well following transfection for $48 \mathrm{~h}$. The DMEM medium containing 10\% FBS was replaced every 3 days. The cells were then cultured in complete medium for 2 weeks. After cell colonies formed, the medium was removed. The cells were fixed with $4 \%$ paraformaldehyde at $4^{\circ} \mathrm{C}$ for $1 \mathrm{~h}$ and stained with $0.1 \%$ crystal violet staining solution for $20 \mathrm{~min}$ at room temperature. Finally, the colony number in each well (colony comprising >50 cells) was counted under a light microscope (Nikon Corporation; 
magnification, $\mathrm{x} 10$ ) and the colony-formation rate was calculated.

Wound healing assay. TU-177 and AMC-HN-8 cells were first seeded into 12-well plates and grown until $90 \%$ confluence. The cellular monolayer was then wounded using a sterilized $200-\mu 1$ pipette tip and the cells were incubated at $37^{\circ} \mathrm{C}$ in serum-free medium. Microscopic images of the cultures were acquired at 0 and $48 \mathrm{~h}$ under a light microscope (magnification, $\mathrm{x} 100$ ), following which wound closure was quantified and then assessed from the images using Scion Image software 4.0.2 (Scion Corporation) and Adobe Photoshop Program 7.0 (Adobe Corporation) (21).

Transwell invasion assay. For cell invasion assay, the insert ( $8.0 \mu \mathrm{m}$ pore size; BD Biosciences) was coated with $0.2 \mathrm{mg} / \mathrm{ml}$ Matrigel (Sigma-Aldrich; Merck KGaA) at $4^{\circ} \mathrm{C}$ for 3-4 h. The TU-177 and AMC-HN-8 cells $\left(5 \times 10^{4}\right.$ cells/well) were first plated into the upper chamber with serum-free medium, whilst the lower chamber was filled with $600 \mu \mathrm{l}$ medium containing $10 \% \mathrm{FBS}$. Following incubation at $37^{\circ} \mathrm{C}$ for $48 \mathrm{~h}$, the cells that invaded to the lower filter and then migrated through the membrane were fixed with $75 \%$ ethanol for $30 \mathrm{~min}$ and stained with $0.1 \%$ crystal violet at room temperature. Finally, the number of invaded cells was counted randomly in five fields of each membrane and imaged under a light microscope (Nikon Corporation; magnification, x100).

Luciferase reporter assay. Firstly, Starbase v2.0 (http://starbase.sysu.edu.cn) was used to predict the target miRNAs of IncRNA MIAT. Subsequently, the sequences of MIAT containing the binding sites of miR-613 were amplified and cloned into the psiCHECK-2 vector (Promega Corporation) and named MIAT-wild type (Wt). The putative common fragments were replaced and named MIAT-mutant (Mut). The TU-177 and AMC-HN-8 cells were seeded at a density of $5 \times 10^{4}$ into 24 -well plates and then co-transfected with luciferase reporter vectors comprising MIAT-Wt or MIAT-Mut $(0.4 \mu \mathrm{g})$, miR-613 mimics $(50 \mathrm{nmol} / \mathrm{l})$ or miR-NC (50 nmol/l) and pRL-TK plasmid (50 ng; Promega Corporation) using Lipofectamine $^{\circledR} 2000$ reagent (Invitrogen; Thermo Fisher Scientific, Inc.). The pRL-TK Renilla luciferase plasmid was used as an internal control for normalization. Following transfection for $48 \mathrm{~h}$, the protein-extraction reagent RIPA Lysis buffer (Gibco; Thermo Fisher Scientific, Inc.) was used to lyse the cells. The luciferase activities were then detected using the Dual-Luciferase Reporter Assay System (Promega Corporation).

RNA immunoprecipitation (RIP) assay. RNA immunoprecipitation (RIP) assay was performed to further confirm the direct association between lncRNA MIAT and miR-613. Magna RIP ${ }^{\text {Tм }}$ RNA Immunoprecipitation kit (EMD Millipore) was used by following the manufacturer's protocols. Briefly, the LSCC cells were transfected with the miR-613 mimics or miR-NC (50 $\mathrm{nM}$ ) for $48 \mathrm{~h}$ before being lysed using the RIP lysis buffer (EMD Millipore). A total of $50 \mu 1$ magnetic beads were resuspended in $100 \mu \mathrm{l}$ RIP washing buffer and swirled. After the supernatant had been discarded, magnetic beads were resuspended with $100 \mu$ l RIP washing buffer, and
$5 \mu \mathrm{g}$ antibodies were added. The magnetic bead-antibody complex was washed and resuspended in $900 \mu \mathrm{l}$ RIP washing buffer before incubation with cell lysates. The cell lysates were then incubated with the RIP buffer containing magnetic bead-antibody complex at $4^{\circ} \mathrm{C}$ overnight. Finally, co-precipitated magnetic bead-protein complex and input were separately detached with proteinase $\mathrm{K}$ to extract RNA for subsequent RT-qPCR detection of MIAT. The antibodies used for RIP were rabbit anti-human Ago2 (1:500; Abcam; cat. no. ab186733) and rabbit anti-human IgG (1:500; Abcam; cat. no. ab109489).

Statistical analysis. Statistical analysis was performed using GraphPad Prism 6.0 (GraphPad Software, Inc.) and SPSS version 20.0 software (IBM, Corp.). All experiments were independently repeated in triplicate. Data are presented as the means \pm standard deviation. Differences among multiple groups were analyzed using one-way ANOVA followed by Tukey's test, whilst differences between two groups were analyzed using Student's t-test. Correlation between MIAT and miR-613 expression was estimated using Pearson's correlation coefficient. $\mathrm{P}<0.05$ was considered to indicate a statistically significant difference.

\section{Results}

IncRNA MIAT expression is upregulated in LSCC tissues and cell lines. The expression of IncRNA MIAT in LSCC tissues and cell lines was measured using RT-qPCR. The relative expression of lncRNA MIAT in LSCC tissue samples was significantly increased compared with that in the adjacent non-tumor tissues (Fig. 1A). In addition, the expression levels of IncRNA MIAT were significantly higher in the LSCC cell lines TU686, TU-177 and AMC-HN-8 compared with those in the control HaCaT cell line (Fig. 1B). As the relative level of MIAT was higher in TU-177 and AMC-HN-8 cells, these cell lines were selected for further experimentation.

Knockdown of MIAT inhibits the proliferation of LSCC cells. To investigate the effects of lncRNA MIAT on the viability of LSCC cells further, small interfering RNA specifically targeting MIAT (si-MIAT) or si-NC were transfected into the TU-177 and AMC-HN-8 cells. Transfection efficiency was confirmed by RT-qPCR (Fig. 2A), where the expression levels of MIAT were significantly decreased in the two LSCC cell lines transfected with si-MIAT compared with those in the si-NC group. The cell viability curves as determined by MTT assay revealed that following MIAT knockdown, the viabilities of the TU-177 and AMC-HN-8 cell lines were significantly inhibited at $72 \mathrm{~h}$ (Fig. 2B). In addition, it was found that knocking down MIAT expression significantly reduced the number of colonies formed by the TU-177 and AMC-HN-8 cells (Fig. 2C).

Knockdown of MIAT inhibits the migration and invasion of LSCC cells. The migratory and invasive abilities of LSCC cells was next examined using wound healing and Transwell invasion assays, respectively. The migratory ability of TU-177 and AMC-HN-8 cells was significantly decreased following MIAT knockdown (Fig. 3A). It was also found that MIAT 

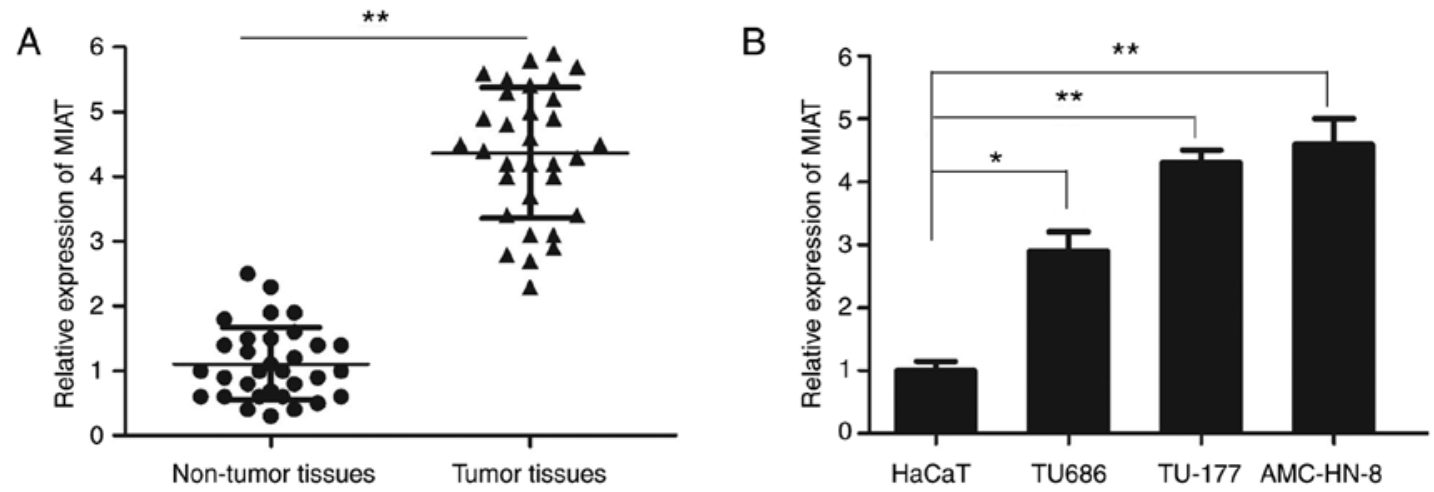

Figure 1. IncRNA MIAT expression is upregulated in LSCC tissues and cell lines. (A) The expression of MIAT in LSCC tissues and adjacent non-tumor tissues was detected by RT-qPCR. (B) Expression levels of MIAT in LSCC cell lines TU686, TU-177 and AMC-HN-8 and the normal non-cancerous HaCaT cells were measured by RT-qPCR. "P<0.05 and ${ }^{* *} \mathrm{P}<0.01$. IncRNA, Long non-coding RNA; MIAT, myocardial infarction associated transcript; LSCC, laryngeal squamous cell carcinoma; RT-qPCR, reverse transcription-quantitative PCR.
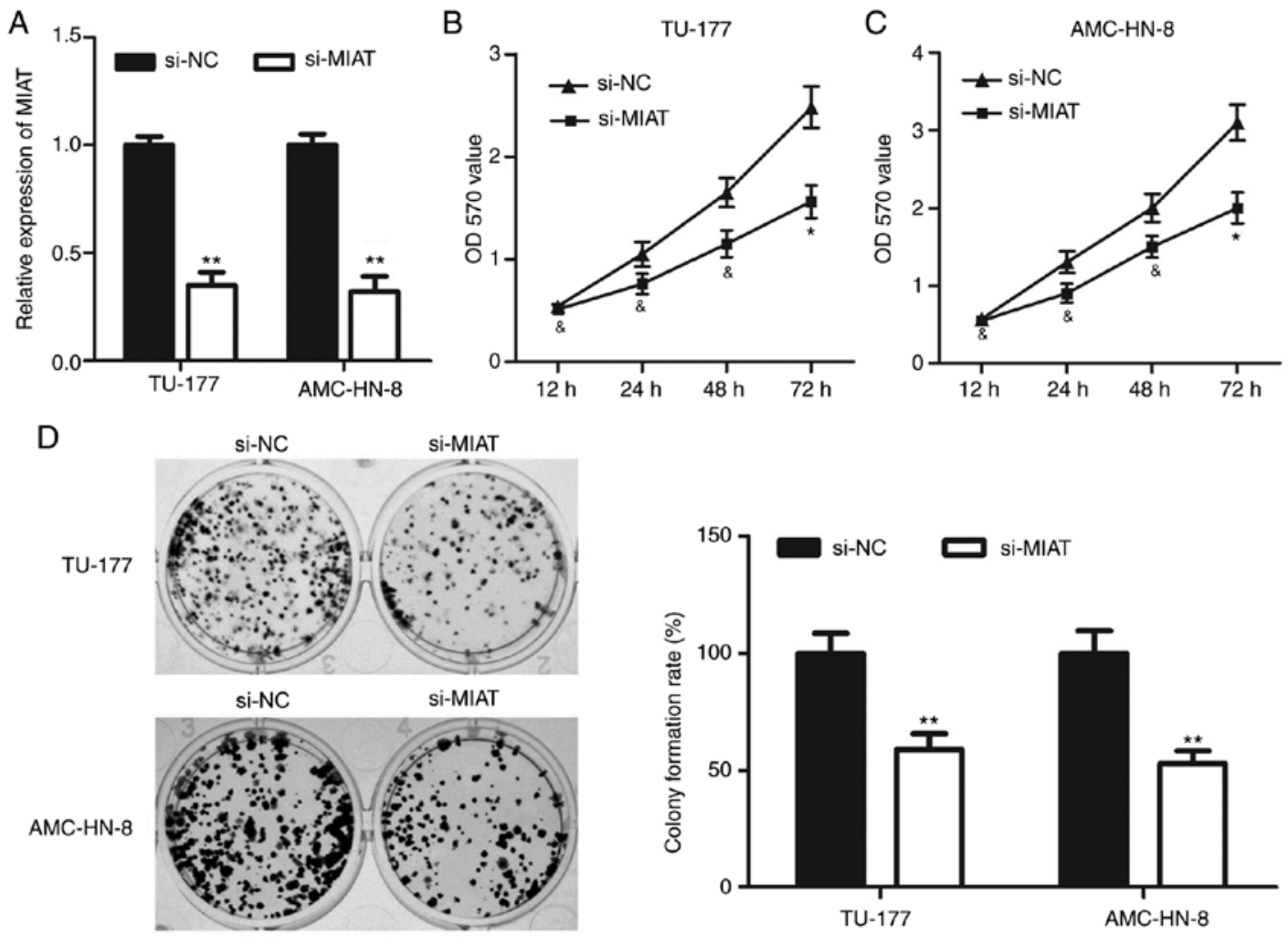

Figure 2. MIAT knockdown inhibits LSCC cell proliferation and colony formation. (A) Transfection efficacy of si-MIAT in TU-177 and AMC-HN-8 cells MTT assay revealed that MIAT knockdown reduced the viability of (B) TU-177 and (C) AMC-HN-8 cells. (D) Colony formation assay showed that MIAT knockdown reduced the number of colonies in TU-177 and AMC-HN-8 cells. ${ }^{*} \mathrm{P}<0.05,{ }^{* *} \mathrm{P}<0.01$ and ${ }^{\star} \mathrm{P}>0.05$ vs. si-NC. MIAT, myocardial infarction associated transcript; LSCC, laryngeal squamous cell carcinoma; OD, optical density; NC, negative control.

knockdown significantly reduced the number of invasive TU-177 and AMC-HN-8 cells (Fig. 3B).

lncRNA MIAT directly binds miR-613 in LSCC cells. To further elucidate the molecular mechanisms of action of lncRNA MIAT in regulating the biological behaviors of LSCC cells, the binding sites of MIAT were predicted using Starbase v2.0 (https://starbase.sysu.edu.cn). Previous studies have demonstrated that miR-613 is a tumor suppressor that can inhibit cell proliferation and invasion in a number of types of cancer, including LSCC (22-24). Therefore, the present study focused on miR-613 among these miRNAs that were predicted to interact with MIAT. IncRNA MIAT was found to contain a complimentary binding site of miR-613 (Fig. 4A). The expression level of miR-613 was also significantly upregulated in both TU-177 and AMC-HN-8 cells after transfection with miR-613 mimics compared with that after transfection with miR-NC (Fig. 4B). By contrast, the level of miR-613 expression was significantly downregulated after transfection with anti-miR-613 in both TU-177 and AMC-HN-8 cells mimics compared with that after transfection with anti-miR-NC (Fig. 4C). Subsequently, the targeted 
A

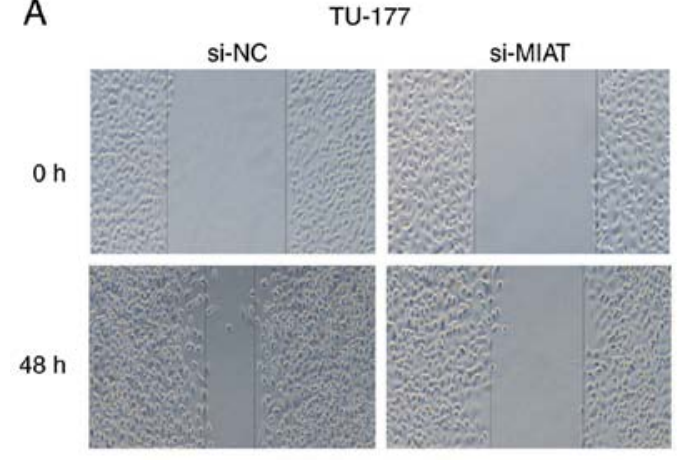

AMC-HN-8
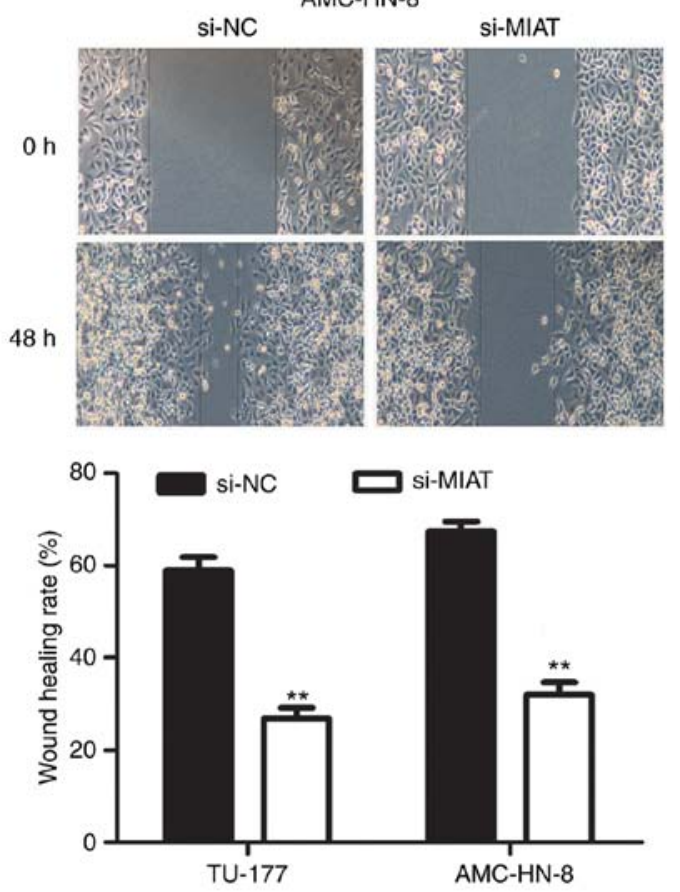

B
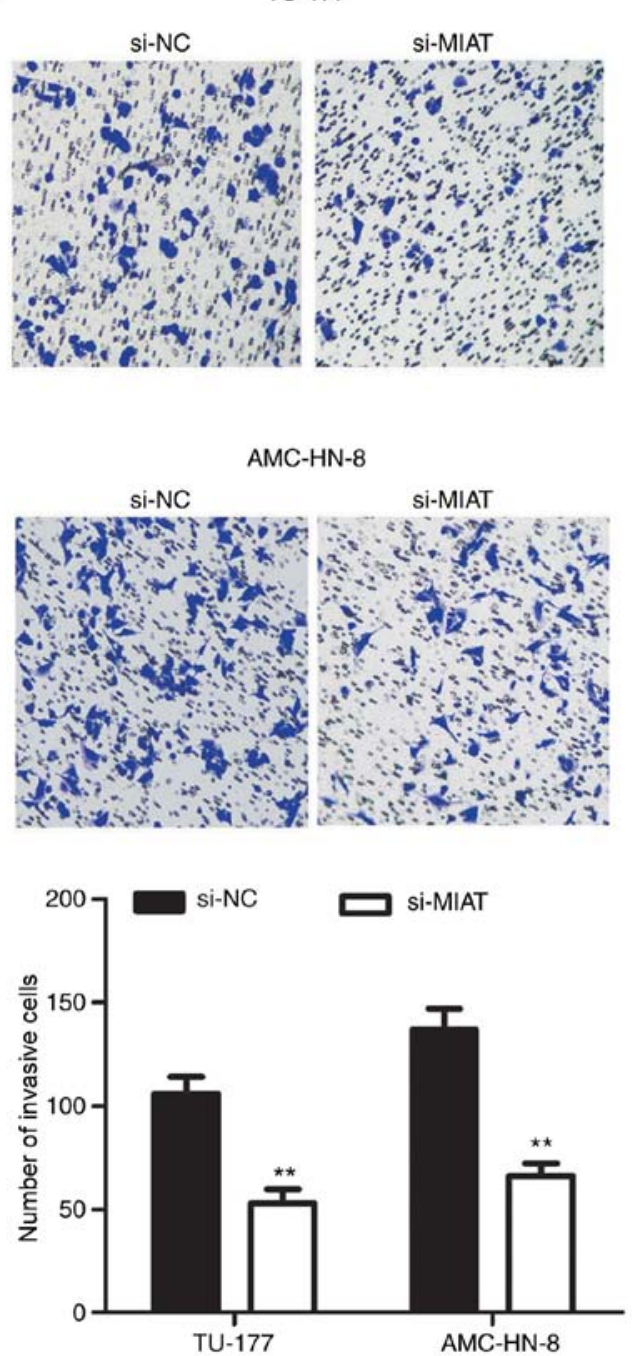

Figure 3. Knockdown of MIAT inhibits the migration and invasion of LSCC cells. (A) Wound healing assay and (B) Transwell assay were used to examine the migration of TU-177 and AMC-HN-8 cells following MIAT knockdown (magnification, $\mathrm{x} 100$ ). ${ }^{* *} \mathrm{P}<0.01$ vs. si-NC. MIAT, myocardial infarction associated transcript; LSCC, laryngeal squamous cell carcinoma.

effects of miR-613 on MIAT were validated using luciferase reporter assay. The results revealed that co-transfection with the MIAT wild-type luciferase reporter and miR-613 mimics significantly reduced the luciferase activity compared with that after co-transfection with MIAT wild-type luciferase reporter and miR-NC (Fig. 4D and E). However, no marked changes were observed in the luciferase activity of the MIAT mutant luciferase reporter group in the TU-177 and AMC-HN-8 cells after co-transfection with miR-613 (Fig. 4D and E). These data strongly suggest that miR-613 specifically binds to MIAT. Subsequently, it was found that the knockdown of MIAT significantly increased miR-613 expression in the TU-177 and AMC-HN-8 cells (Fig. 4F). Therefore, RIP assay was performed to elucidate the possible endogenous association between MIAT and miR-613. Transfection with the miR-613 mimics led to a significant enrichment of MIAT in lysates precipitated using the anti-Ago2 antibody in the TU-177 and AMC-HN-8 cells compared with that after transfection with the miR-NC (Fig. 4G and H). Taken together, these results suggested that lncRNA MIAT can directly bind to miR-613 and function as a sponge of miR-613 in LSCC.
miR-613 expression is downregulated in human LSCC tissues and cell lines and inversely correlates with MIAT expression. The expression levels of miR-613 in the three LSCC cell lines TU686, TU-177 and AMC-HN-8 and the $\mathrm{HaCaT}$ cell line, in addition to those in the LSCC tissues and the corresponding adjacent non-tumor tissues were also measured using RT-qPCR. The expression level of miR-613 was significantly lower in the three LSCC cells compared with that in $\mathrm{HaCaT}$ cells (Fig. 5A). Additionally, it was found that the expression of miR-613 was also significantly lower in LSCC tissues compared with that in adjacent non-tumor tissues (Fig. 5B). Pearson's correlation analysis was subsequently performed to examine the correlation between MIAT and miR-613 expression in LSCC tissues. The expression level of miR-613 correlated inversely with that of MIAT expression in LSCC tissue samples (Fig. 5C).

Overexpression of miR-613 inhibits the progression of LSCC. To investigate the role of miR-613 in the proliferative, migratory and invasive ability of LSCC cells, miR-613 mimics or miR-NC was transfected into TU-177 and AMC-HN-8 
A
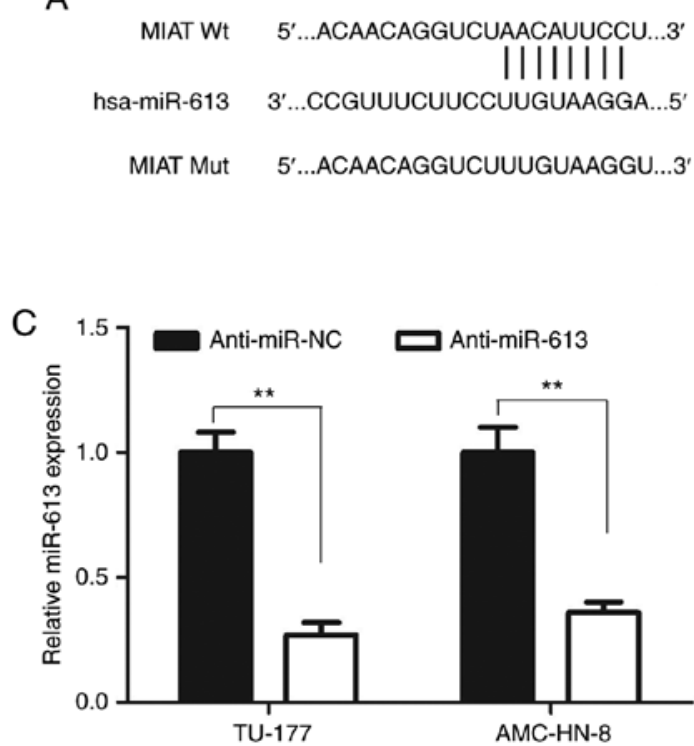

E

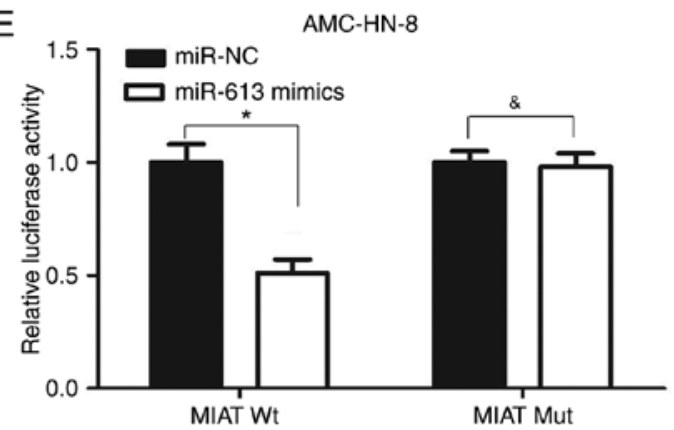

G

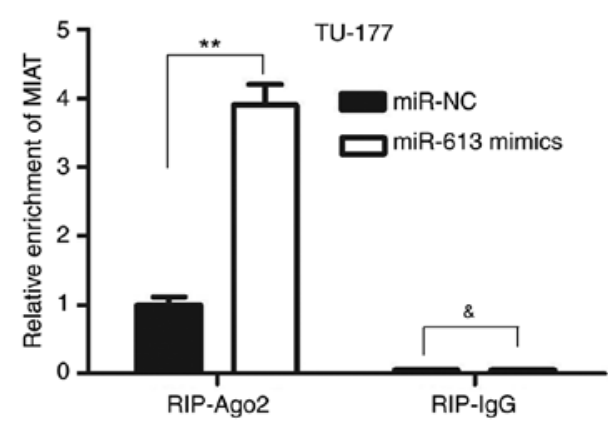

B

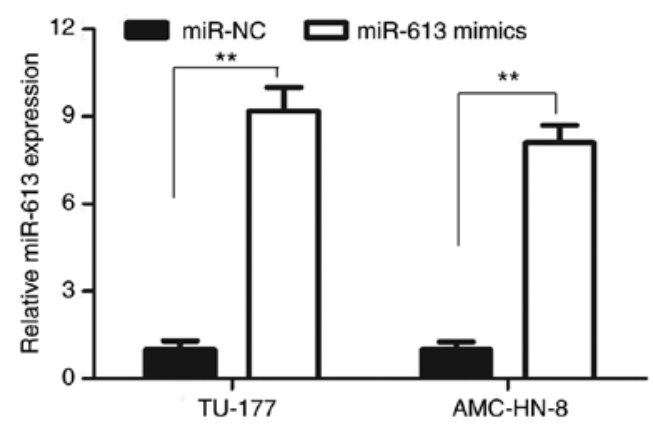

D

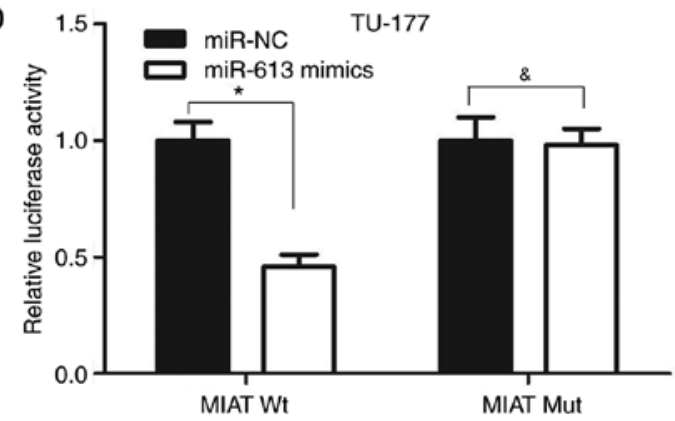

$\mathrm{F}$

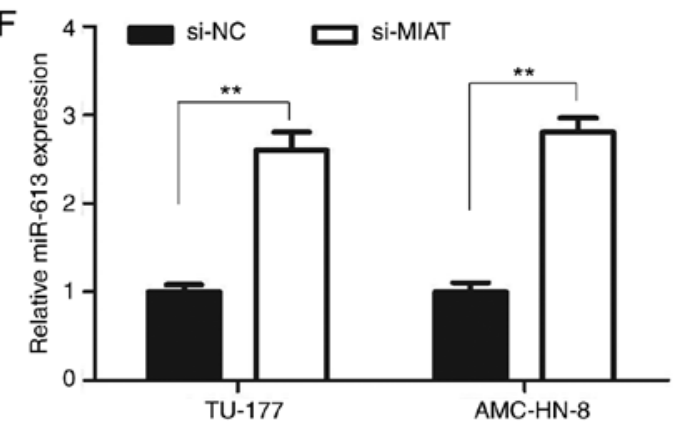

$\mathrm{H}$

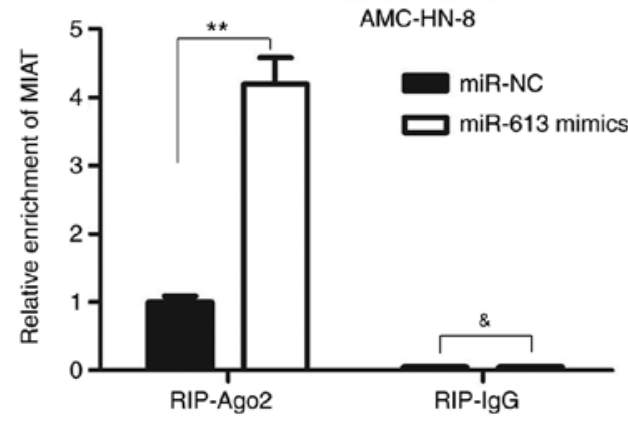

Figure 4. MIAT directly interacts with miR-613. (A) The potential binding sites between MIAT and miR-613, and the mutant sequence in the seed region. Relative expression level of miR-613 was measured by RT-qPCR after transfection with (B) miR-613 mimics or (C) anti-miR-613, compared with cells transfected with corresponding negative controls. Luciferase reporter gene assay verified that MIAT could directly bind to miR-613 in (D) TU-177 and (E) AMC-HN-8 cells. (F) The expression levels of miR-613 after MIAT knockdown in TU-177 and AMC-HN-8 cells were measured by RT-qPCR. (G) TU-177 and (H) AMC-HN-8 cells were transfected with miR-613 mimics or the control, followed by the measurement of MIAT mRNA after enrichment with anti-Ago2 by RT-qPCR. Anti-IgG was used as a negative control. ${ }^{*} \mathrm{P}<0.05,{ }^{* *} \mathrm{P}<0.01$ and ${ }^{\circledR} \mathrm{P}>0.05$. MIAT, myocardial infarction associated transcript; UTR, untranslated region; RT-qPCR, reverse transcription-quantitative PCR; miR, microRNA.

cells. The cell viability at $72 \mathrm{~h}$ and colony formation ability of TU-177 and AMC-HN-8 cells in the miR-613 mimics group were significantly reduced compared with those in the miR-NC group (Fig. 6A-C). In addition, the migratory ability of the TU-177 and AMC-HN-8 cells was significantly decreased following miR-613 overexpression compared with that after miR-NC transfection (Fig. 6D). It was also found that overexpression of miR-613 significantly reduced the number of invasive TU-177 and AMC-HN-8 cells compared with that after miR-NC transfection (Fig. 6E).

Inhibition of miR-613 reverses the effects of IncRNA MIAT knockdown on the proliferation and invasion of LSCC cells. To further investigate whether IncRNA MIAT promotes the proliferation, migratory and invasive abilities of LSCC cells by negatively regulating miR-613 expression, anti-miR-613 

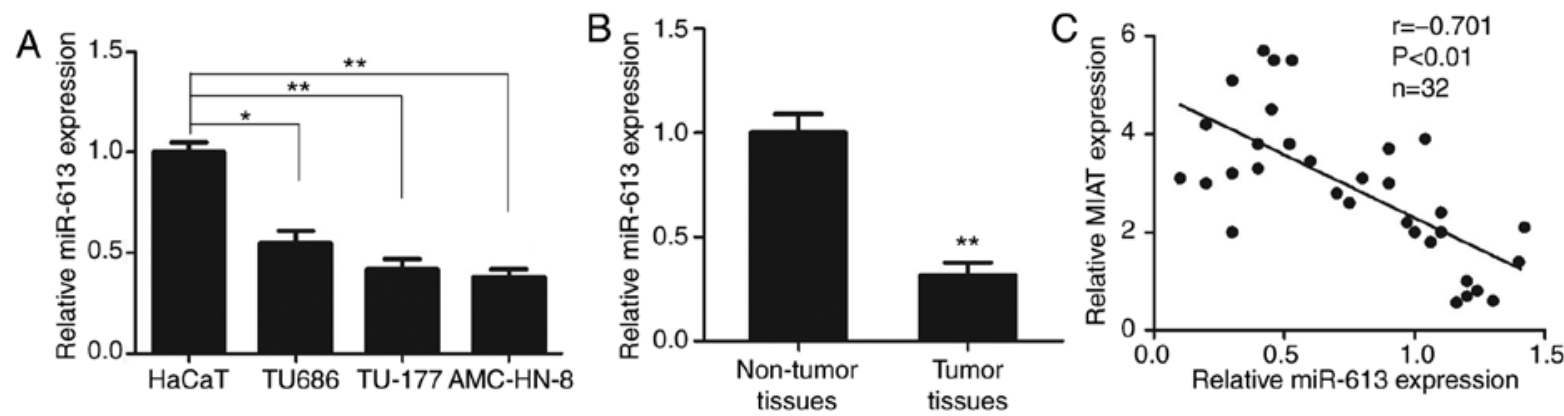

Figure 5. miR-613 expression is downregulated in LSCC tissues and cells and inversely correlates with MIAT expression. (A) The expression of miR-613 in LSCC cell lines TU686, TU-177 and AMC-HN-8 and HaCaT cells was detected by RT-qPCR. (B) The expression of miR-613 in LSCC tissues and adjacent non-tumor tissues was detected by RT-qPCR. (C) Correlation between MIAT and miR-613 expression levels was examined in LSCC tissues. ${ }^{*} \mathrm{P}<0.05$, ${ }^{* * *} \mathrm{P}<0.01$. LSCC, laryngeal squamous cell carcinoma; MIAT, myocardial infarction associated transcript; miR, microRNA; RT-qPCR, reverse transcription-quantitative PCR.

was transfected into TU-177 and AMC-HN-8 cells where MIAT expression was also knocked down. Downregulation of miR-613 markedly reversed the inhibitory effects of si-MIAT on the viability of TU-177 and AMC-HN-8 cells at $72 \mathrm{~h}$ (Fig. 7A and B). In addition, the colony forming efficiency of the TU-177 and AMC-HN-8 cells was significantly increased in the si-MIAT + anti-miR-613 group compared with that in the si-MIAT + anti-miR-NC group (Fig. 7C and D). It was also found that the downregulation of miR-613 significantly reversed the inhibitory effects of si-MIAT on the migration and invasion of TU-177 and AMC-HN-8 cells (Fig. 7E-G).

\section{Discussion}

LSCC accounts for $>90 \%$ of all laryngeal cancer (LCa) cases, which is one of the most commonly observed malignancies of the head and neck (25). Risk factors for LSCC include alcohol consumption, a history of smoking, older age and male sex (26). Surgery is one of the main treatment methods for this disease, but the surgical resection margin is generally insufficient for treating patients presenting with perineural invasion (27). Mesolella et al (28) previously reported that it is important to complement the surgical therapeutic treatment with adjuvant radiotherapy. In spite of synthetic serial treatments, including surgical intervention, chemotherapy and radiation therapy, long-term prognosis of patients with LSCC remains largely unsatisfactory (29). Therefore, understanding of the precise molecular mechanisms underlying the pathogenesis of LSCC and identifying novel targeted treatments for LSCC remain important issues that need to be addressed.

The occurrence and progression of LSCC require complex biological processes involving multiple genetic and epigenetic changes. Recent studies have highlighted that multiple types of RNA, including IncRNAs, circular RNAs and microRNAs, can all regulate the expression levels of mRNA to serve important roles in LSCC (30-32). Takeuchi et al (33) recently reported that a number of microRNAs, including miR-9, miR-10b, miR-21 and miR-132 are aberrantly upregulated in LCa, where they can contribute to the aggressiveness of the LCa. In addition, miR-449a upregulation was found to inhibit cell invasion and motility, suppressed cell proliferation and induced the downregulation of Notch1 and Notch2 in the LCa cell line HEP-2 (34). At present, there are no valid prognostic factors that can systematically drive the choice of nodal treatment for
LCa. Ricciardiello et al (35) previously identified 20 miRNAs specific for $\mathrm{LCa}$ and a tissue-specific miRNA signature that is predictive of lymph node metastases. In laryngeal carcinoma characterized by 11 miRNAs, seven of which were found to be upregulated and four were downregulated (36). IncRNAs are a novel class of RNAs that do not encode proteins and contribute to the development and progression of malignant tumors (7). An increasing number of studies have suggested that lncRNA dysregulation is involved in epigenetic alterations to serve important roles in the tumorigenesis and metastasis of various types of tumors, including breast cancer (37), osteosarcoma (38), NSCLC (39) and colorectal cancer (40). Of note, IncRNAs, including NEAT1 (10), H19 (41), taurine upregulated-1 (42) and plasmacytoma variant translocation 1 (PVT1) (43), function as oncogenes to promote the aggressive phenotypes of LSCC, whilst RP11-169D4.1 (44), neighboring enhancer of FOXA2 (45) and maternally expressed 3 (46) function as tumor suppressors in LSCC. In addition, IncRNAs have been reported to be important regulators of gene expression and represent an innovative pharmacological target as molecular biomarkers of LSCC (30).

Currently, an increasing number of studies have reported that lncRNA MIAT serves an important role in the initiation and development of malignant tumors. In particular, MIAT has been shown to enhance papillary thyroid cancer growth and metastasis by binding miR-324-3p and upregulating LIM and SH3 protein 1 (47). IncRNA MIAT also serves as a key factor to promote cell invasion, migration and proliferation through the PI3K/AKT signaling pathway in melanoma (48). In addition, it promotes cell migration and invasion in NCSLC by sponging miR-1246 (49). In the present study, one major finding was that lncRNA MIAT was significantly upregulated in LSCC tissues and cell lines (TU686, TU-177 and AMC-HN-8), where the MIAT expression level was higher in TU-177 and AMC-HN-8. Therefore, TU-177 and AMC-HN-8 were chosen to evaluate the effects of MIAT on LSCC cells. The results revealed that the knockdown of MIAT expression exerted inhibitory effects on LSCC cell proliferation, migration and invasion. This suggest that MIAT promotes the tumorigenesis of LSCC and may function as an oncogene. However, it is a limitation for the lack of parallel experiments on the TU686 cell line in the present study. Additionally, further investigation is required to elucidate the role of MIAT in the progression of LSCC in vivo in future studies. 


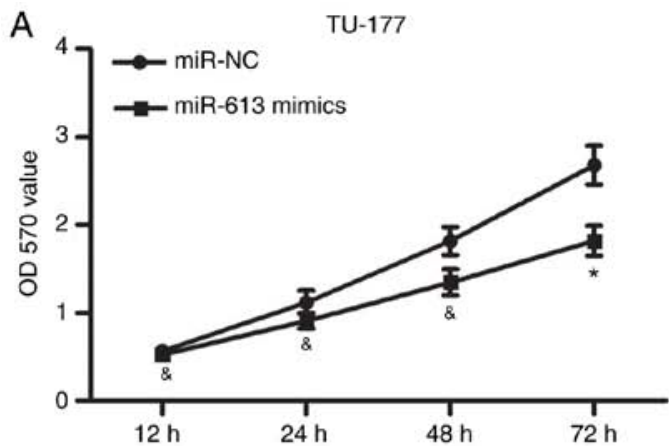

B

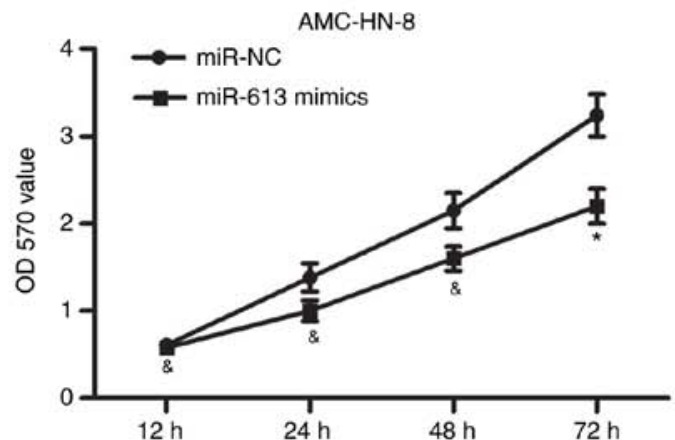

C

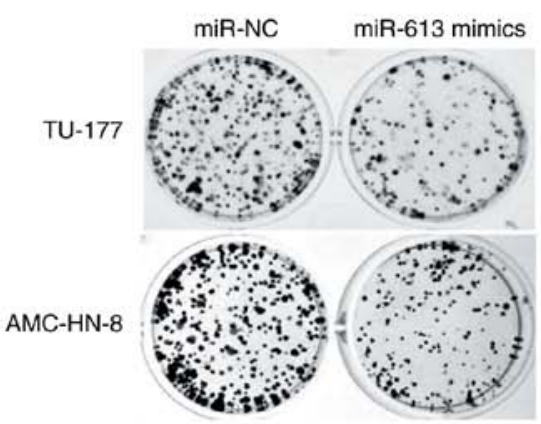

D

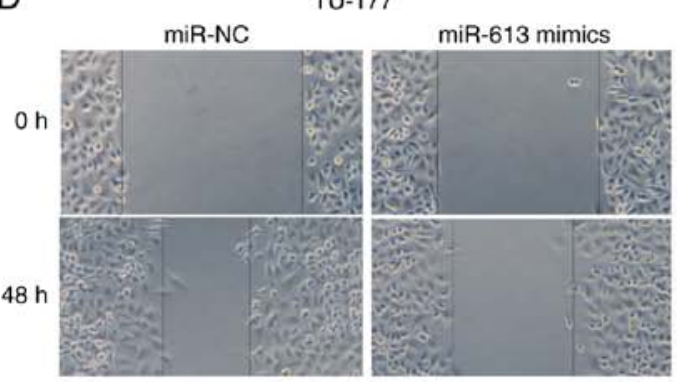

AMC-HN-8
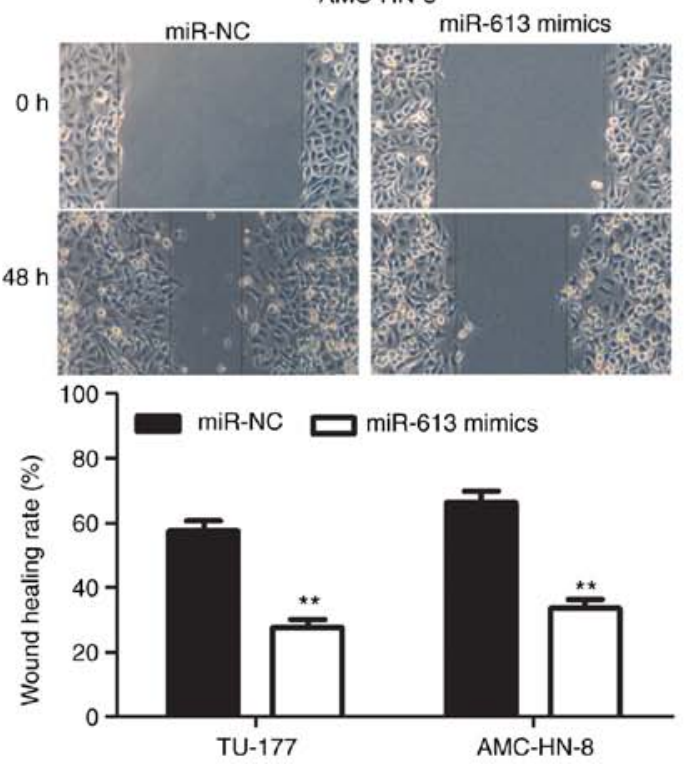

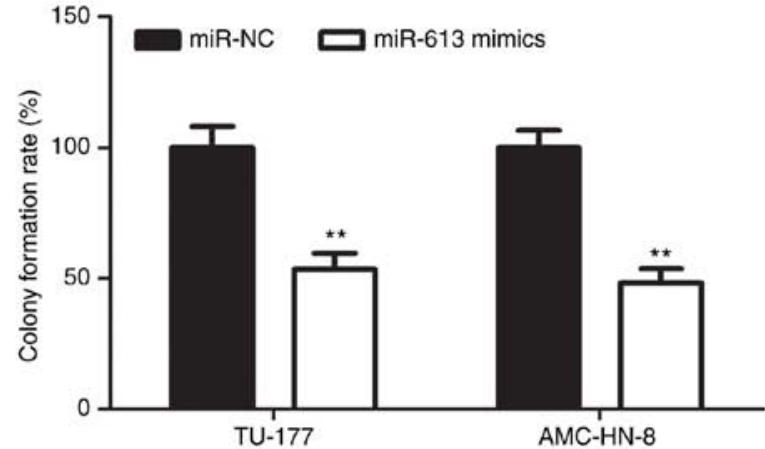

E

AMC-HN-8

miR-613 mimics

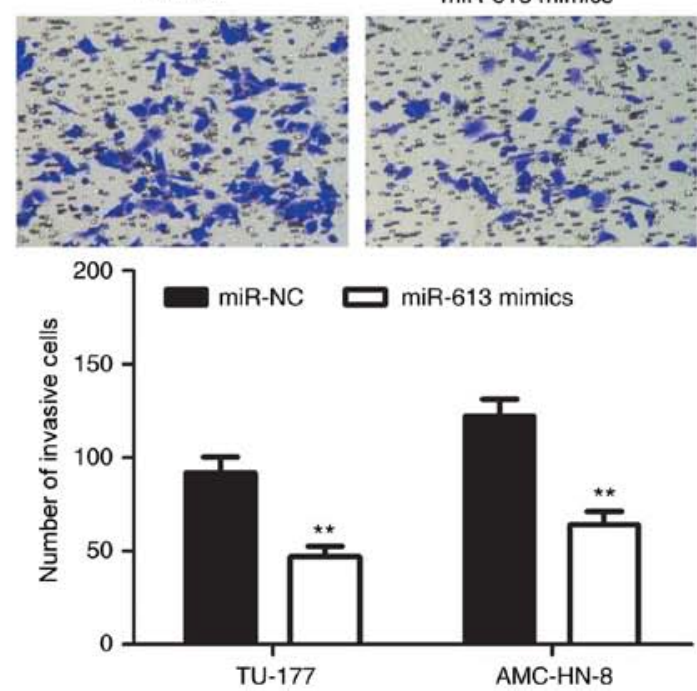

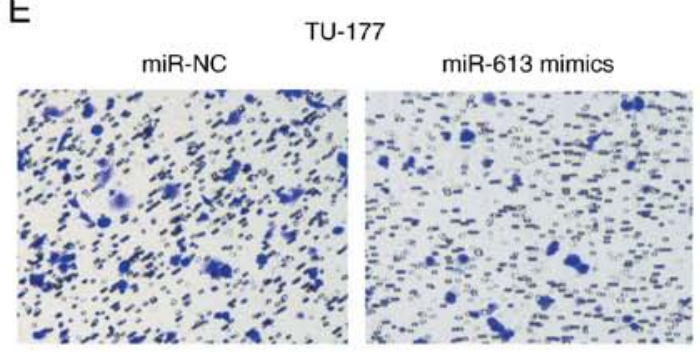

Figure 6. Overexpression of miR-613 inhibits the progression of LSCC. MTT assay revealed that overexpression of miR-613 reduced the viability of (A) TU-177 and (B) AMC-HN-8 cells. (C) Colony formation assay showed that overexpression of miR-613 significantly reduced the number of colonies in TU-177 and AMC-HN-8 cells. The migratory and invasive ability of the LSCC cells was examined by (D) wound healing assay and (E) Transwell invasion assay, respectively (magnification, $\mathrm{x} 100$ ). ${ }^{*} \mathrm{P}<0.05,{ }^{* * *} \mathrm{P}<0.01$ and ${ }^{\circledR} \mathrm{P}>0.05$ vs. miR-NC. LSCC, laryngeal squamous cell carcinoma; miR, microRNA; NC, negative control.

Recent studies have demonstrated that lncRNAs serve a role in cancer development as ceRNAs that can sponge miRNAs (50-52). IncRNA PVT1 has been previously shown to function as an oncogene in the development of LSCC, partly by sponging miR-519d-3p and inhibiting its expression (43). In the present study, bioinformatics analysis 

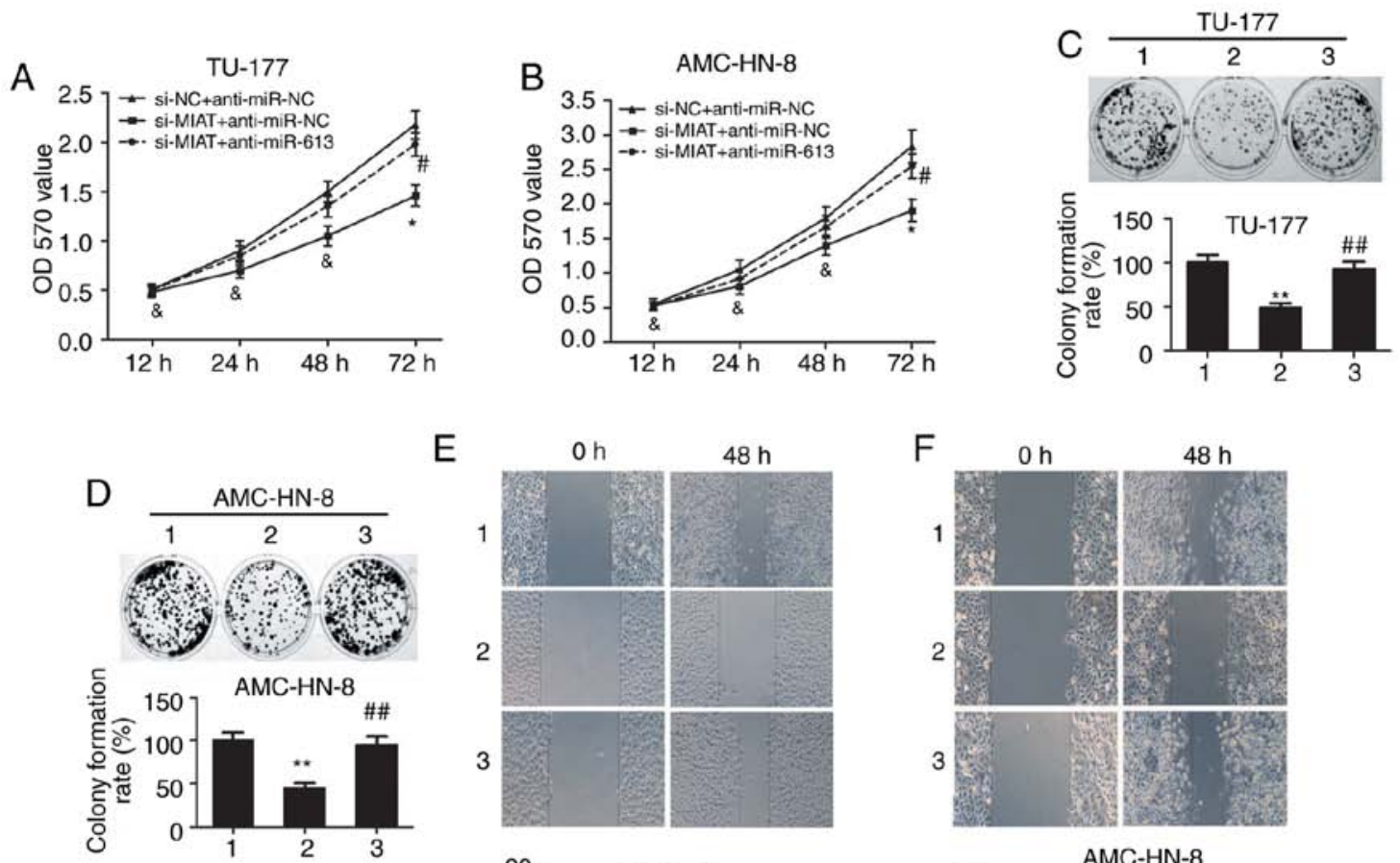

E

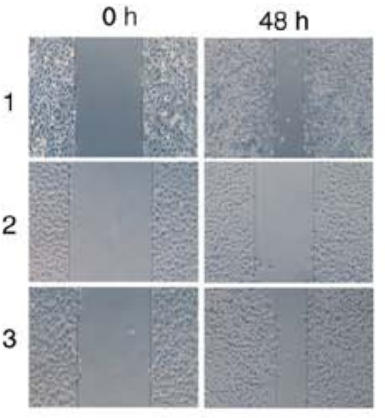

F $\quad 0 \mathrm{~h}$
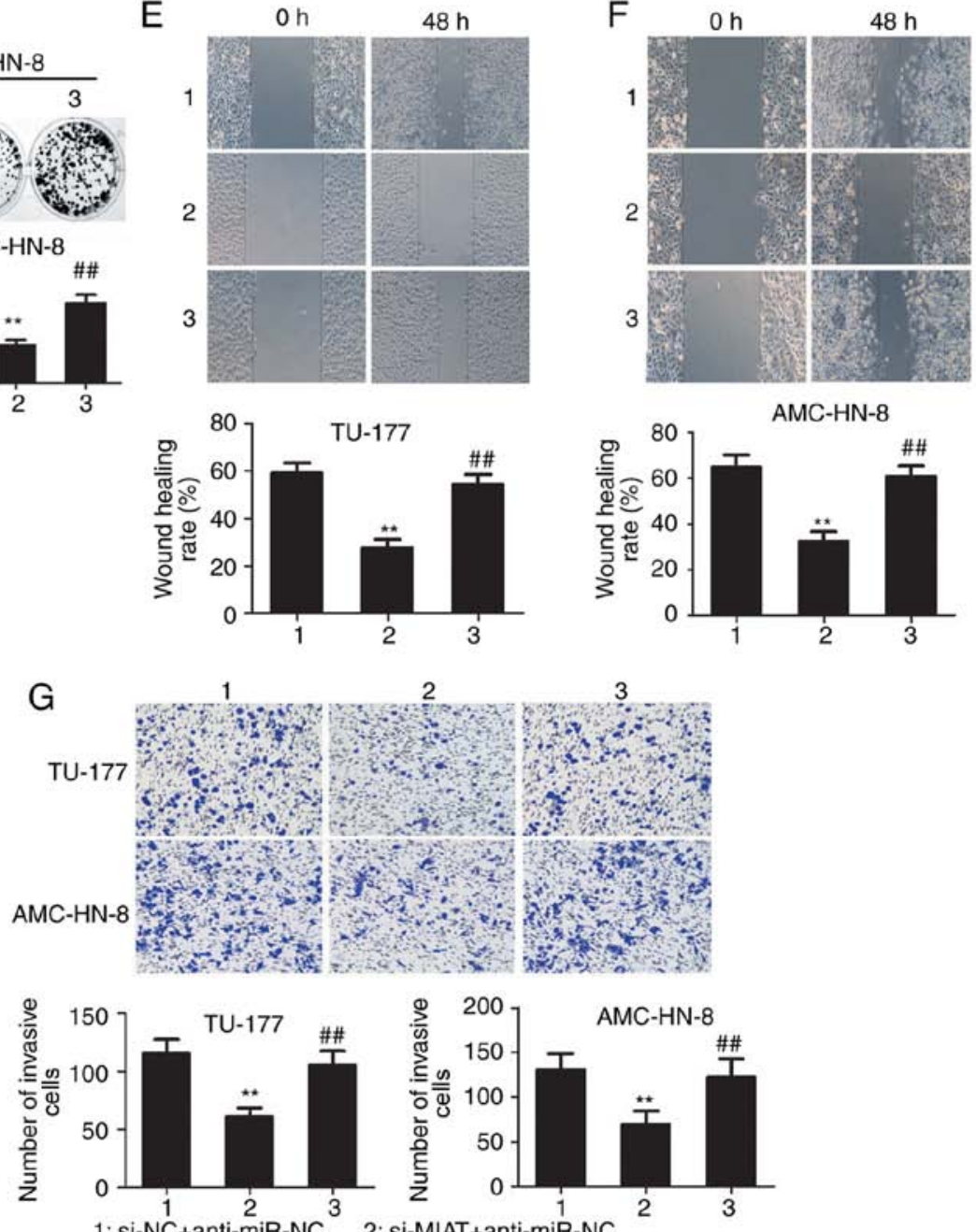

3: si-MIAT+anti-miR-613

Figure 7. IncRNA MIAT promotes LSCC development by regulating miR-613 expression. The effects of co-transfection of si-MIAT and anti-miR-613 on the viability of (A) TU-177 and (B) AMC-HN-8 cells were detected by MTT assay. The effects of co-transfection of si-MIAT and anti-miR-613 on the proliferation of (C) TU-177 and (D) AMC-HN-8 cells were detected by colony formation assay. The effects of co-transfection of si-MIAT and anti-miR-613 on the migratory ability of (E) TU-177 and (F) AMC-HN-8 cells were detected using wound healing assay (magnification, x100). (G) Transwell assay were used to examine TU-177 and AMC-HN-8 cell invasion after si-MIAT and anti-miR-613 co-transfection (magnification, $\mathrm{x} 100$ ). ${ }^{*} \mathrm{P}<0.05,{ }^{* *} \mathrm{P}<0.01$ and ${ }^{\&} \mathrm{P}>0.05$, si-MIAT + anti-miR-NC group vs. si-NC + anti-miR-NC group; ${ }^{\#} \mathrm{P}<0.05$, ${ }^{\# /} \mathrm{P}<0.01$ and ${ }^{\circledR} \mathrm{P}>0.05$, si-MIAT + anti-miR-613 group vs. si-MIAT + anti-miR-NC group. MIAT, myocardial infarction associated transcript; OD, optical density; NC, negative control; miR, microRNA.

predicted that several potential complementary sites existed between MIAT and miR-613, which was verified further using luciferase reporter assay in TU-177 and AMC-HN-8 cells. Notably, it was found that the knockdown of MIAT increased miR-613 expression, where MIAT acted as a miR-613 sponge in LSCC as shown by results from RIP assays. In addition, it was found that miR-613 was expressed at lower levels in LSCC tissues, where its expression negatively correlated with MIAT expression. According to these results, it can be suggested that a reciprocal relationship exists between miR-613 and MIAT expression in LSCC. Previous studies have revealed that miR-613 acts as either an oncogene or a tumor suppressor $(22,23,53-56)$. miR-613 expression was documented to be significantly upregulated 
in cervical cancer (CC) tissues and cells, which promotes the cell proliferation, invasion and migration of $\mathrm{CC}$ by targeting protein tyrosine phosphatase non-receptor type 9 (53). Similarly, miR-613 functions as an oncogene in colon cancer, where it promotes cell proliferation, invasion and migration by targeting protein atonal homolog 1 , likely by activating the JNK1 pathway (54). Furthermore, previous studies have also indicated that miR-613 inhibits the progression of NSCLC (22), pancreatic cancer (23), breast cancer (55) and gastric cancer (56). Wang et al (57) reported that miR-613 serves as a tumor suppressor gene in LSCC partly by inhibiting phosphoinositide-dependent kinase-1 expression. In the present study, the expression of miR-613 was markedly downregulated in LSCC cell lines, such that the overexpression of miR-613 inhibited the proliferation, migration and invasion of LSCC cells. To investigate whether lncRNA MIAT promotes the progression of LSCC by regulating miR-613, anti-miR-613 was transfected into TU-177 and AMC-HN-8 cells, where MIAT expression was also knocked down. The data revealed that the knockdown of miR-613 restored the proliferative, migratory and invasive activities in LSCC cells following MIAT silencing, suggesting that MIAT may promote the malignant progression of LSCC by sponging miR-613.

In conclusion, the present study, to the best of our knowledge, was the first to demonstrate that MIAT functions as a novel tumor-promoting IncRNA in LSCC. In addition, MIAT functions as a ceRNA to negatively regulate the expression of miR-613 by competitive binding, thereby promoting the tumorigenesis and development of LSCC.

\section{Acknowledgements}

Not applicable.

\section{Funding}

No funding was received.

\section{Availability of data and materials}

The datasets used and/or analyzed during the current study are available from the corresponding author on reasonable request.

\section{Authors' contributions}

FS and YY designed the study and performed the experiments. JL performed statistical analysis and revised the manuscript. FS, YY and JL confirmed the authenticity of all the raw data. All authors read and approved the final version of the manuscript.

\section{Ethics approval and consent to participate}

All patients signed informed consent prior to the use of their tissues for the present study according to the principles of the Declaration of Helsinki. The present study was approved by the Ethics Committee of Tianjin Union Medical Center (Tianjin, China).

\section{Patient consent for publication}

Not applicable.

\section{Competing interests}

The authors declare that they have no competing interests.

\section{References}

1. Siegel RL, Miller KD and Jemal A: Cancer statistics, 2015. CA Cancer J Clin 65: 5-29, 2015.

2. Bray F, Ferlay J, Soerjomataram I, Siegel RL, Torre LA and Jemal A: Global cancer statistics 2018: GLOBOCAN estimates of incidence and mortality worldwide for 36 cancers in 185 countries. CA Cancer J Clin 68: 394-424, 2018.

3. Marur S and Forastiere AA: Head and neck squamous cell carcinoma: Update on epidemiology, diagnosis, and treatment. Mayo Clin Proc 91: 386-396, 2016.

4. Almadori G, Bussu F, Cadoni G, Galli J, Paludetti G and Maurizi M: Molecular markers in laryngeal squamous cell carcinoma: Towards an integrated clinicobiological approach. Eur J Cancer 41: 683-693, 2005.

5. Yang L, Froberg JE and Lee JT: Long noncoding RNAs: Fresh perspectives into the RNA world. Trends Biochem Sci 39: 35-43, 2014.

6. Choudhry H, Harris AL and McIntyre A: The tumour hypoxia induced non-coding transcriptome. Mol Aspects Med 47-48: 35-53, 2016.

7. Peng WX, Koirala $\mathrm{P}$ and Mo YY: lncRNA-mediated regulation of cell signaling in cancer. Oncogene 36: 5661-5667, 2017.

8. Shen Z, Hao W, Zhou C, Deng H, Ye D, Li Q, Lin L, Cao B and Guo J: Long non-coding RNA AC026166.2-001 inhibits cell proliferation and migration in laryngeal squamous cell carcinoma by regulating the miR-24-3p/p27 axis. Sci Rep 8: 3375, 2018.

9. Wang R, Ma Z, Feng L, Yang Y, Tan C, Shi Q, Lian M, He S, Ma H and Fang J: lncRNA MIR31HG targets HIF1A and P21 to facilitate head and neck cancer cell proliferation and tumorigenesis by promoting cell-cycle progression. Mol Cancer 17: 162, 2018.

10. Wang $\mathrm{P}, \mathrm{Wu} \mathrm{T}$, Zhou H, Jin Q, He G, Yu H, Xuan L, Wang X, Tian L, Sun Y, et al: Long noncoding RNA NEAT1 promotes laryngeal squamous cell cancer through regulating miR-107/CDK6 pathway. J Exp Clin Cancer Res 35: 22, 2016.

11. Hao YR, Zhang DJ, Fu ZM, Guo YY and Guan GF: Long non-coding RNA ANRIL promotes proliferation, clonogenicity, invasion and migration of laryngeal squamous cell carcinoma by regulating miR-181a/Snai2 axis. Regen Ther 11: 282-289, 2019.

12. Ishii N, Ozaki K, Sato H, Mizuno H, Saito S, Takahashi A, Miyamoto $\mathrm{Y}$, Ikegawa $\mathrm{S}$, Kamatani $\mathrm{N}$, Hori $\mathrm{M}$, et al: Identification of a novel non-coding RNA, MIAT, that confers risk of myocardial infarction. J Hum Genet 51: 1087-1099, 2006.

13. Sha M, Lin M, Wang J, Ye J, Xu J, Xu N and Huang J: Long non-coding RNA MIAT promotes gastric cancer growth and metastasis through regulation of miR-141/DDX5 pathway. J Exp Clin Cancer Res 37: 58, 2018.

14. Zhang HY, Zheng FS, Yang $\mathrm{W}$ and Lu JB: The long non-coding RNA MIAT regulates zinc finger E-box binding homeobox 1 expression by sponging miR-150 and promoting cell invasion in non-small cell lung cancer. Gene 633: 61-65, 2017.

15. Qu Y, Xiao H, Xiao W, Xiong Z, Hu W, Gao Y, Ru Z, Wang C, Bao L, Wang K, et al: Upregulation of MIAT regulates LOXL2 expression by competitively binding miR-29c in clear cell renal cell carcinoma. Cell Physiol Biochem 48: 1075-1087, 2018.

16. Liu Z, Wang H, Cai H, Hong Y, Li Y, Su D and Fan Z: Long non-coding RNA MIAT promotes growth and metastasis of colorectal cancer cells through regulation of miR-132/Derlin-1 pathway. Cancer Cell Int 18: 59, 2018.

17. Barnes L, Eveson JW, Reichart P and Sidransky D: WHO pathology and genetic classification of tumors of head and neck tumours. 3rd edition, Lyon, IARC Press, pp107-162, 2005.

18. Li Y, Tao C, Dai L, Cui C, Chen C, Wu H, Wei Q and Zhou X: MicroRNA-625 inhibits cell invasion and epithelialmesenchymal transition by targeting SOX4 in laryngeal squamous cell carcinoma. Biosci Rep 39: BSR20181882, 2019. 
19. Nowinska K, Ciesielska U, Piotrowska A, Jablonska K Partynska A, Paprocka M, Zatonski T, Podhorska-Okolow M and Dziegiel P: MCM5 expression is associated with the grade of malignancy and Ki-67 antigen in LSCC. Anticancer Res 39: 2325-2335, 2019.

20. Livak KJ and Schmittgen TD: Analysis of relative gene expression data using real-time quantitative PCR and the 2(-Delta Delta C(T)) method. Methods 25: 402-408, 2001.

21. Giordano C, Barone I, Vircillo V, Panza S, Malivindi R, Gelsomino L, Pellegrino M, Rago V, Mauro L, Lanzino M, et al: Activated FXR inhibits leptin signaling and counteracts tumor-promoting activities of cancer-associated fibroblasts in breast malignancy. Sci Rep 6: 21782, 2016.

22. Li D, Li DQ, Liu D and Tang XJ: miR-613 induces cell cycle arrest by targeting CDK4 in non-small cell lung cancer. Cell Oncol (Dordr) 39: 139-147, 2016.

23. Cai H, Yao J, An Y, Chen X, Chen W, Wu D, Luo B, Yang Y, Jiang Y, Sun D and He X: lncRNA HOTAIR acts a competing endogenous RNA to control the expression of notch 3 via sponging miR-613 in pancreatic cancer. Oncotarget 8: 32905-32917, 2017.

24. Xiong H, Yan T, Zhang W, Shi F, Jiang X, Wang X, Li S, Chen Y, Chen $\mathrm{C}$ and Zhu Y: miR-613 inhibits cell migration and invasion by downregulating Daam1 in triple-negative breast cancer. Cell Signal 44: 33-42, 2018

25. Marioni G, Marchese-Ragona R, Cartei G, Marchese F and Staffieri A: Current opinion in diagnosis and treatment of laryngeal carcinoma. Cancer Treat Rev 32: 504-515, 2006.

26. Menach P, Oburra HO and Patel A: Cigarette smoking and alcohol ingestion as risk factors for laryngeal squamous cell carcinoma at Kenyatta National Hospital, Kenya. Clin Med Insights Ear Nose Throat 5: 17-24, 2012.

27. Nix P, Cawkwell L, Patmore H, Greenman J and Stafford N: $\mathrm{Bcl}-2$ expression predicts radiotherapy failure in laryngeal cancer. Br J Cancer 92: 2185-2189, 2005.

28. Mesolella M, Iorio B, Misso G, Luce A, Cimmino M, Iengo M, Landi M, Sperlongano P, Caraglia M and Ricciardiello F: Role of perineural invasion as a prognostic factor in laryngeal cancer. Oncol Lett 11: 2595-2598, 2016.

29. Chu EA and Kim YJ: Laryngeal cancer: Diagnosis and preoperative work-up. Otolaryngol Clin North Am 41: 673-695, 2008

30. Cossu AM, Mosca L, Zappavigna S, Misso G, Bocchetti M De Micco F, Quagliuolo L, Porcelli M, Caraglia M and Boccellino M: Long non-coding RNAs as important biomarkers in laryngeal cancer and other head and neck tumours. Int J Mol Sci 20: 3444, 2019.

31. Ekmekci CG, Coskunpinar E, Avci H, Farooqi AA, Orhan KS and Akbas F: Integrative analysis of mRNA and microRNA expression profiles in laryngeal squamous cell carcinoma. J Cell Biochem 120: 3415-3422, 2019.

32. Zhao X, Zhang W and Ji W: miR-196b is a prognostic factor of human laryngeal squamous cell carcinoma and promotes tumor progression by targeting SOCS2. Biochem Biophys Res Commun 501: 584-592, 2018

33. Takeuchi T, Kawasaki H, Luce A, Cossu AM, Misso G Scrima M, Bocchetti M, Ricciardiello F, Caraglia M and Zappavigna S: Insight toward the microRNA profiling of laryngeal cancers: Biological role and clinical impact. Int J Mol Sci 21: 3693, 2020

34. Kawasaki H, Takeuchi T, Ricciardiello F, Lombardi A, Biganzoli E, Fornili M, De Bortoli D, Mesolella M, Cossu AM, Scrima M, et al: Definition of miRNA signatures of nodal metastasis in LCa: miR-449a targets notch genes and suppresses cell migration and invasion. Mol Ther Nucleic Acids 20: 711-724, 2020 .

35. Ricciardiello F, Capasso R, Kawasaki H, Abate T, Oliva F Lombardi A, Misso G, Ingrosso D, Leone CA, Iengo $M$ and Caraglia M: A miRNA signature suggestive of nodal metastases from laryngeal carcinoma. Acta Otorhinolaryngol Ital 37: 467-474, 2017.

36. Lian Y, Li Z, Fan Y, Huang Q, Chen J, Liu W, Xiao C and Xu H The lncRNA-HOXA-AS2/EZH2/LSD1 oncogene complex promotes cell proliferation in pancreatic cancer. Am J Trans Res 9: 5496-5506, 2017

37. Liu XM, Yang B and Han J: Increased long noncoding RNA LINP1 expression and its prognostic significance in human breast cancer. Eur Rev Med Pharmacol Sci 22: 8749-8754, 2018.
38. Li H, Tian G, Tian F and Shao L: Long non-coding RNA TUG1 promotes osteosarcoma cell proliferation and invasion through inhibition of microRNA-212-3p expression. Exp Ther Med 16 779-787, 2018

39. Zhang G, An X, Zhao H, Zhang Q and Zhao H: Long non-coding RNA HNF1A-AS1 promotes cell proliferation and invasion via regulating miR-17-5p in non-small cell lung cancer. Biomed Pharmacother 98: 594-599, 2018.

40. Liu Y, Zhou J, Wang S, Song Y, Zhou J and Ren F: Long non-coding RNA SNHG12 promotes proliferation and invasion of colorectal cancer cells by acting as a molecular sponge of microRNA-16. Exp Ther Med 18: 1212-1220, 2019.

41. Guan GF, Zhang DJ, Wen LJ, Xin D, Liu Y, Yu DJ, Su K, Zhu L, Guo YY and Wang K: Overexpression of lncRNA H19/miR-675 promotes tumorigenesis in head and neck squamous cell carcinoma. Int J Med Sci 13: 914-922, 2016

42. Zhang Z, Wang X, Cao S, Han X, Wang Z, Zhao X, Liu X, Li G, Pan X and Lei D: The long noncoding RNA TUG1 promotes laryngeal cancer proliferation and migration. Cell Physiol Biochem 49: 2511-2520, 2018.

43. Zheng $\mathrm{X}$, Zhao K, Liu T, Liu L, Zhou $\mathrm{C}$ and $\mathrm{Xu}$ M: Long noncoding RNA PVT1 promotes laryngeal squamous cell carcinoma development by acting as a molecular sponge to regulate miR-519d-3p. J Cell Biochem 120: 3911-3921, 2019.

44. Zhao J, Lv K, Li ZH, Wu J, Gao W, Wong TS, Luo J, Qin H, Wang B, Fu Q and Lei WB: Functional significance of the long non-coding RNA RP11-169D4.1 as a metastasis suppressor in laryngeal squamous cell carcinoma by regulating CDH1. Oncol Rep 38: 211-220, 2017

45. Cui X, Fang N, Cui Y, Xiao D and Wang X: Long non-coding RNA NEF inhibits proliferation and promotes apoptosis of laryngeal squamous cell carcinoma cells by inhibiting Wnt/ $\beta$-catenin signaling. Oncol Lett 17: 4928-4934, 2019.

46. Zhang X, Wu N, Wang J and Li Z: lncRNA MEG3 inhibits cell proliferation and induces apoptosis in laryngeal cancer via miR-23a/APAF-1 axis. J Cell Mol Med 23: 6708-6719, 2019.

47. Liu W, Wang Z, Wang C and Ai Z: Long non-coding RNA MIAT promotes papillary thyroid cancer progression through upregulating LASP1. Cancer Cell Int 19: 194, 2019.

48. Yang Y, Zhang Z, Wu Z, Lin W and Yu M: Downregulation of the expression of the lncRNA MIAT inhibits melanoma migration and invasion through the PI3K/AKT signaling pathway. Cancer Biomark 24: 203-211, 2019.

49. Lin D, Xu HP, Lin JH, Hu HH, Wang Q and Zhang J: Long non-coding RNA MIAT promotes non-small cell lung cancer progression by sponging miR-1246. Eur Rev Med Pharmacol Sci 23: 5795-5801, 2019.

50. Kartha RV and Subramanian S: Competing endogenous RNAs (ceRNAs): New entrants to the intricacies of gene regulation. Front Genet 5: 8, 2014.

51. Russo F, Fiscon G, Conte F, Rizzo M, Paci P and Pellegrini M: Interplay between long noncoding RNAs and microRNAs in cancer. Methods Mol Biol 1819: 75-92, 2018.

52. Denzler R, McGeary SE, Title AC, Agarwal V, Bartel DP and Stoffel M: Impact of microRNA levels, target-site complementarity, and cooperativity on competing endogenous RNA-regulated gene expression. Mol Cell 64: 565-579, 2016.

53. Li WT, Wang BL, Yang CS, Lang BC and Lin YZ: miR-613 promotes cell proliferation and invasion in cervical cancer via targeting PTPN9. Eur Rev Med Pharmacol Sci 22: 4107-4114, 2018.

54. Yang X, Zhang L, Song X, He W, Zhang D, Lu Q, Wu J, Wu C and Jiang J: MicroRNA-613 promotes colon cancer cell proliferation, invasion and migration by targeting ATOH1. Biochem Biophys Res Commun 504: 827-833, 2018.

55. Wu J, Yuan P, Mao Q, Lu P, Xie T, Yang H and Wang C: miR-613 inhibits proliferation and invasion of breast cancer cell via VEGFA. Biochem Biophys Res Commun 478: 274-278, 2016.

56. Lu Y, Tang L, Zhang Q, Zhang Z and Wei W: MicroRNA-613 inhibits the progression of gastric cancer by targeting CDK9. Artif Cells Nanomed Biotechnol 46: 980-984, 2018.

57. Wang J, Yang S, Ge W, Wang Y, Han C and Li M: miR-613 suppressed the laryngeal squamous cell carcinoma progression through regulating PDK1. J Cell Biochem 119: 5118-5125, 2018.

This work is licensed under a Creative Commons Attribution-NonCommercial-NoDerivatives 4.0 International (CC BY-NC-ND 4.0) License. 